showed that after growth for one to two years in the bodies of guinea-pigs and mice the virulence for guinea-pigs had neither increased nor that for fowls decreased.

In accordance with the statements of French authors, Weber and Bofinger were able to produce typical cultures of mammalian tubercle bacilli from the organs of a tuberculous parrot. On the other hand, they also succeeded in obtaining from the caseated mesenteric glands of a young pig, which showed no other signs of tuberculosis, a typical culture of the bacillus of fowl tuberculosis.

Under natural conditions, therefore, neither had the bacilli of mammalian tuberculosis undergone conversion in the body of a bird into those of avian tuberculosis, nor had the bacilli of avian tuberculosis in the body of a mammal become converted into those of mammalian tuberculosis. (Tuberkulose Arbeiten, aus dem Kaiserlichen Gesundheitsamte, I904, Heft I., p. I48.)

\title{
ON THE PRESENCE OF TUBERCLE BACILLI IN THE MILK OF COWS WHICH ONLY REACT TO TUBER- CULIN.
}

\section{By Stenström.}

STENSTRöm first recounts the most important works referring to the above question, and particularly the more recent investigations of Rabinowitsch, Kempner, and Ostertag.

Rabinowitsch and Kempner found, in animals which reacted to tuberculin but showed no clinical appearances of tuberculosis, that the milk occasionally contained tubercle bacilli.

On the contrary, Ostertag, who also experimented with the milk of cows which reacted to tuberculin but showed no clinical signs of tuberculosis, never found tubercle bacilli.

Ostertag, who has investigated this question very thoroughly, in a large number of animals made experiments by feeding calves and pigs with the milk of cows which had reacted. In these cases also he was unable to discover any infection with tubercle bacilli.

Stenström's experiments were carried out in the bacteriological laboratory of the "Separator" Company in Hamra, on cows intended for slaughter. "As far as possible antiseptic precautions were observed: The milk was withdrawn into sterile vessels, passed through a centrifugal apparatus rotating at the rate of 3000 to 5000 turns per minute, and the deposit so obtained was mixed with the cream and used to inoculate rabbits intraperitoneally.

In some cases rabbits and guinea-pigs were simultaneously inoculated. Fifty cows were so tested, sixty-eight rabbits and fifteen guinea-pigs being inoculated. The cows had all reacted to tuberculin; several had shown clinical symptoms of tuberculosis, and on post-mortem examination revealed somewhat well-developed changes. One rabbit died from peritonitis. The other experimental animals died or were killed within two to five months after inoculation. None of them proved to be infected with tuberculosis. (Zeits. f. Fleisch and Milchhygiene, May 1904, p. 277, and Rev. generale du lait, 1902, No. 2I.) 